\title{
Produção e manejo agrícola: impactos e desafios para sustentabilidade ambiental
}

\author{
Agricultural production and management: impacts and challenges for \\ environmental sustainability \\ João Fernando Zamberlan', Carlos Otávio Zamberlan², Vitor Francisco Schuch Jr³, \\ Clandia Maffini Gomes ${ }^{4}$, Jordana Marques Kneipp ${ }^{5}$
}

$\square$

\section{RESUMO}

O desenvolvimento econômico e social de uma região deve estar baseado nos princípios da sustentabilidade ambiental, pois, não sendo assim, corre-se o risco de se deixar para as gerações futuras uma herança de escassez e miséria. Portanto, este trabalho procurou identificar os tipos de produção e manejos dados às áreas agrícolas. Foi realizado com produtores de hortifrutigranjeiros dos municípios de Silveira Martins, Nova Palma e Ivorá, no Rio Grande do Sul, selecionados por sua área territorial encontrar-se inserida nas encostas da Serra Geral, cuja fragilidade ambiental é maior. Foram aplicados questionários do tipo fechado a todos os produtores de hortifrutigranjeiros dos referidos municípios com base em listas fornecidas pelas secretarias de agricultura municipais e Condesus. Concluiu-se que a maioria dos cultivos se dá nas encostas pela própria topografia regional. A maioria dos produtores conduz suas atividades para produção e comércio e são majoritariamente conscientes dos riscos e interessados em projetos que viabilizem a unidade de produção de forma sustentável.

Palavras-chave: gestão ambiental, encostas, produção agrícola.

\begin{abstract}
The socioeconomic development of a region must be based on principles of environmental sustainability; otherwise, we may leave our future generations a legacy of shortage and misery. Therefore, this work aims at identifying the types of production and management in agricultural areas. The study was conducted with farmers from Silveira Martins, Nova Palma and Ivorá in Rio Grande do Sul State. These areas were selected due to their location - sloping lands of Serra Geral, whose environmental fragility is significant. Closed-ended questionnaires were used with all Horticulture Agro-industrial farmers studied, based on lists provided by the cities' agriculture departments and Condesus. The results indicate that the majority of crops take place in sloping lands because of the regional topography. Most of farmers conduct their activities for production and commerce and are aware of the risks and become interested in projects that enable the unit of production in a sustainable way.
\end{abstract}

Keywords: environmental management, sloping land, agricultural production.

\section{INTRODUÇÃO}

Em 1877, foi criada a Quarta Colônia de Imigração Italiana na região central do Rio Grande do Sul. Com a vinda dos imigrantes italianos, houve a necessidade de se produzirem alimentos e se construírem residências e estruturas na nova terra. Com isso, deu-se início ao processo de depleção dos recursos naturais devido à retirada de madeira e à abertura de áreas para instalação dos cultivos agrícolas. As áreas de florestas cederam espaço à agricultura e retirada de madeiras nobres, promovendo, desta forma, o processo de fragmentação das florestas (ITAQUI, 2002). Atualmente, a base econômica dos municípios da região é a agricultura, principalmente de batata inglesa, fumo, milho e feijão (ITAQUI, 2002).

\section{口-}

'Mestrado e Doutorado em Engenharia Agrícola pela Universidade Federal de Santa Maria (UFSM) - Santa Maria (RS), Brasil; Professor da Universidade de Cruz Alta - Santa Maria (RS), Brasil.

2Doutorado em Economia do Desenvolvimento pela Universidade Federal do Rio Grande do Sul (UFRGS) - Professor da Universidade Estadual de Mato Grosso do Sul (UEMS) Ivinhema (MS), Brasil.

[3Doutorado em Educação pela Universidade Estadual de Campinas (Unicamp) - Campinas (SP), Brasil; Professor Colaborador Voluntário, no Curso de Graduação em Administração da UFSM - Santa Maria (RS), Brasil.

${ }^{4}$ Doutorado em Administração pela Universidade de São Paulo (USP) - São Paulo (SP), Brasil; Professora da UFSM - Santa Maria (RS), Brasil.

${ }^{5}$ Doutoranda em Administração pela UFSM; Professora da UFSM - Santa Maria (RS), Brasil

Endereço para correspondência: João Fernando Zamberlan - Campus Universitário Dr. Ulysses Guimarães - Rodovia Municipal Jacob Della Méa, km 5.6 - Parada Benito 98020-290 - Cruz Alta (RS), Brasil - E-mail: jfzamberlan@gmail.com

Recebido em: 23/10/12 - Aceito em: 13/05/14 - Reg. ABES: 680 
Segundo Marcuzzo et al. (1998), essa região ainda mantém uma parcela de Mata Atlântica, considerada uma reserva de Biosfera. É uma área rica em recursos florestais, animais e hídricos, além de ser um lugar privilegiado por sua beleza natural. Portanto, as atividades agrícolas e econômicas desenvolvidas na região devem utilizar-se dos recursos naturais como solo e água de maneira racional e sustentável.

A utilização do solo pelas atividades agrícolas promove alterações nos processos biológicos, físicos e químicos do ambiente, e tais alterações devem ser monitoradas e avaliadas a fim de que ações corretivas da degradação que por ventura exista possam ser implementadas (MERTEN \& MINELLA, 2002). Segundo Lago e Pádua (1984), deve-se optar por um crescimento econômico controlado que minimize os impactos ambientais e proporcione equidade social. A utilização de tecnologias que reduzam o impacto ambiental na produção agrícola é de suma importância para que fique assegurada a capacidade de satisfazer as necessidades das futuras gerações, ou seja, a sustentabilidade.

Atualmente, o modelo produtivo parece ter feito desaparecer os condicionantes físicos que obrigam o homem a se adaptar às diferentes condições de solo, água, topografia e clima (LEFF, 2002). Na última década do século 20, houve mudanças como globalização, aumento no fluxo de informações, revolução tecnológica, dando início à filosofia da responsabilidade social e ambiental (VERDOLIN \& ALVES, 2005).

A gestão ambiental é uma ferramenta que deve ser introduzida nas atividades realizadas pelas unidades de produção agrícola regionais. Segundo Neumann e Loch (2002), no caso do Brasil, os instrumentos de gestão ambiental pública são essencialmente compostos por instrumentos de comando e controle, atribuindo-se penalidades. A implementação de uma gestão ambiental dentro das organizações, incorporando uma variável ambiental junto à produção, utilizando racionalmente os recursos naturais, adotando novas tecnologias que permitam minimizar os impactos ambientais é uma estratégia que possibilita utilizar de maneira mais eficiente os recursos naturais como, por exemplo, a água.

A necessidade de área para o cultivo de alimentos, mesmo que no início tenha sido somente para subsistência, tornou-se fonte de renda para as famílias da região. Legalmente, a área não pode sofrer alterações para o uso agrícola, restringindo a sua expansão. Também se somam as questões legais, a desvalorização de seu trabalho, obrigando os produtores, muitas vezes, a saírem de suas terras, pois com a queda de preço dos produtos e o cultivo de commodities em áreas reduzidas já não são remunerados como anteriormente.

O cultivo agrícola em áreas de encostas está mais suscetível à degradação do solo e da água devido às acentuadas declividades. O fato de se manter o solo exposto sem cobertura vegetal reduz a taxa de infiltração de água, aumentando o deflúvio superficial, ocorrendo desta forma o carreamento de material para jusante, promovendo a sedimentação e alterando o estado qualitativo dos corpos hídricos de maneira nociva.

A produção de commodities necessita ser feita em grande escala, para que a remuneração do produtor seja adequada às suas necessidades.
Na região da Quarta Colônia de Imigração Italiana, a própria topografia do terreno é um empecilho, não sendo possível a expansão de novas áreas devido à legislação ambiental.

Este trabalho teve como objetivo identificar o grau de conscientização de produtores rurais e a aplicação de técnicas e manejos conservacionistas por parte das unidades de produção agrícola com vistas à sustentabilidade ambiental.

\section{MATERIAL E MÉTODOS}

O presente estudo foi realizado com produtores de hortifrutigranjeiros na região da Quarta Colônia de Imigração Italiana, localizada entre as coordenadas geográficas 2909'15,39”e 2958'37,68” de latitude sul, $53^{\circ} 01^{\prime} 53^{\prime \prime}$ e 5355'12" de longitude oeste, nos municípios de Silveira Martins, Ivorá e Nova Palma no Estado do Rio Grande do Sul.

Esses municípios foram escolhidos dentre os demais que compõem a região da Quarta Colônia porque a maior parte de suas terras estão inseridas em área de encosta com grandes declividades, maiores que $45^{\circ}$ em algumas situações, o que lhes confere maior fragilidade ambiental.

Os solos predominantes na região são os das unidades de mapeamento Ciríaco, Santa Maria e Oásis (BRASIL, 1973). O clima da região, segundo a classificação climática de Köppen, é o Cfa do tipo fundamental temperado úmido, com chuvas bem distribuídas durante o ano, sem estação seca definida, e com temperatura do mês mais quente superior a $22^{\circ} \mathrm{C}$ e do mês mais frio superior a $-3^{\circ} \mathrm{C}$ (MORENO, 1961).

A pesquisa é uma "survey" quantitativa. Para a coleta de dados, foram aplicados questionários estruturados com perguntas fechadas a todos os produtores de hortifrutigranjeiros da região, com base no cadastro fornecido pelas prefeituras municipais e pelo Consórcio de Desenvolvimento da Quarta Colônia (Condesus). Uma equipe com quatro bolsistas e um professor aplicou o questionário nas unidades de produção, em três dias da semana, durante os meses de outubro, novembro e dezembro de 2005 e janeiro de 2006.

O trabalho inicialmente se deu no município de Silveira Martins, sendo posteriormente realizado em Nova Palma e findado no município de Ivorá, seguindo-se a linha de facilidade de acesso.

Todas as unidades de produção foram georreferenciadas por meio de um GPS 12 da Garmin, que posteriormente gerou um mapa da distribuição espacial dos produtores agrícolas dos municípios pesquisados.

Os resultados e as frequências foram analisados estatisticamente pelo programa SPSS 17.

\section{RESULTADOS E DISCUSSÃO}

A produção agrícola regional primeiramente visava somente à subsistência familiar e atualmente ganhou caráter comercial, sendo uma produção bastante diversificada, mas ainda calcada na produção e venda de 
commodities agrícolas. A expansão e abertura de novas áreas na região é uma alternativa de execução impossível, o que força os agricultores mais jovens muitas vezes a saírem de suas propriedades em busca de novas áreas, permanecendo somente os mais velhos.

É necessário desenvolver alternativas de produção que aproveitem a aptidão cultural da região, com a exploração de nichos de mercado ainda descobertos para os produtos ali cultivados e beneficiados.

\section{Tipo de atividade exercida pelo produtor rural}

Com relação à atividade exercida (Tabela 1), no município de Silveira Martins $69,7 \%$ dos produtores se dedicam tanto ao comércio quanto à produção e 21,2\% somente se dedicam a produzir, sem se preocupar com o mercado varejista. Cerca de $9 \%$ dos entrevistados dedicam-se somente à comercialização dos produtos, realizando o papel de intermediário, comprando e revendendo. Em Ivorá, 90\% dedicam-se ao comércio e produção, 9,8\% somente produzem alimentos, e nenhum produtor se dedica exclusivamente ao comércio como única atividade. No município de Nova Palma, $81,8 \%$ vivem da produção e comércio, e 9,1\% para cada uma das outras atividades. A pequena escala de produção, a cultura local, a dificuldade de colocar seus produtos no mercado e a dificuldade de organização entre os produtores, sendo propriedades estritamente familiares, explicam de certa forma os números obtidos e por que a grande maioria se dedica às duas atividades. Portanto, a maioria tem na produção primária sua fonte de renda.

\section{Grau de conscientização do produtor em relação ao cultivo de encostas}

Para qualquer programa ou projeto que vise ao desenvolvimento de uma região é primeiramente necessário procurar identificar o grau de conscientização dos produtores com relação a tipo de área, riscos ambientais e técnicas utilizadas ou não nas unidades de produção agrícola. A Tabela 2 mostra as porcentagens de conscientização dos produtores nos três municípios pesquisados.

Verifica-se que, nos municípios de Silveira Martins e Nova Palma, a maioria dos produtores estão cientes dos riscos ambientais, como também das técnicas de cultivo que minimizam o impacto ambiental. Em Ivorá, 37,1\% dos produtores possuem pouco conhecimento sobre novas técnicas ou mesmo sobre os riscos de degradação das áreas, e $8,6 \%$ não possuem qualquer conhecimento a respeito. Esse valor é bastante preocupante, pois a base econômica municipal é a agricultura,

Tabela 1 - Tipo de atividade exercida pela unidade de produção agrícola.

\begin{tabular}{l|c|c|c|c|c|c}
\multirow{2}{*}{ Alternativas } & \multicolumn{6}{|c|}{ Frequências } \\
\cline { 2 - 8 } & \multicolumn{2}{|c|}{ Silveira Martins } & \multicolumn{2}{|c|}{ Ivorá } & \multicolumn{2}{c}{ Nova Palma } \\
\cline { 2 - 7 } & Absoluta & $\%$ & Absoluta & $\%$ & Absoluta & $\%$ \\
\hline Produção & 7 & 21,2 & 4 & 9,8 & 1 & 9,1 \\
\hline Comércio & 3 & 9,1 & - & - & 1 & 9,1 \\
\hline Produção e comércio & 23 & 69,7 & 37 & 90,2 & 9 & 81,8 \\
\hline Total & 33 & 100,0 & 41 & 100,0 & 11 & 100,0 \\
\hline
\end{tabular}

principalmente do fumo, em que se utiliza uma alta gama de insumos agrícolas em grande quantidade, somada ao intenso movimento do solo, podendo com isso contribuir para a degradação dos recursos naturais.

A educação ambiental é um difusor dos conhecimentos sobre o meio ambiente e indutor das mudanças de práticas e comportamentos, sendo decisiva para adoção de técnicas compatíveis com a preservação dos recursos naturais (CARVALHO, 2001). Para tanto, nesse fato reside o início de uma produção calcada na sustentabilidade.

\section{Proporção de produtores que utilizam as encostas para o cultivo agrícola}

Toda área de encosta está mais suscetível à degradação ambiental devido à topografia acidentada, que no caso de uma enxurrada, por exemplo, corrobora para que a água ganhe velocidade, tendo uma maior energia e poder de desagregação, carreando uma quantidade significativa de solo para sua jusante. A ocupação e o uso dos solos pelas atividades agrícolas interferem e alteram os sistemas naturais (MERTEN \& MINELLA, 2002), com a perda de solo e nutrientes do horizonte mais superficial, impactando negativamente a produção agrícola, do ponto de vista tanto técnico quanto econômico.

A Tabela 3 mostra que, no município de Silveira Martins, 43,5\% dos produtores cultivam as encostas da região, principalmente com culturas anuais, 39,1\% não utilizam essas áreas para cultivo e 17,4\% usam parcialmente ou de vez em quando. Em Ivorá, 74,3\% dos produtores utilizam tais áreas, $17,1 \%$ utilizam pouco e $8,6 \%$ não cultivam nas encostas. No município de Nova Palma também, como nos demais, os produtores utilizam suas áreas de encostas para produzir na proporção de $87,5 \%$ e não utilizam $12,5 \%$. Somando-se as áreas sempre utilizadas e as que o são eventualmente, o município de Ivorá obteve o maior

Tabela 2 - Grau de conscientização dos produtores da Quarta Colônia de Imigração Italiana.

\begin{tabular}{l|c|c|c|c|c|c|c}
\multirow{3}{*}{ Alternativas } & \multicolumn{6}{|c}{ Frequências } \\
\cline { 2 - 8 } & Silveira Martins & \multicolumn{2}{|c}{ Ivorá } & \multicolumn{2}{c}{ Nova Palma } \\
\cline { 2 - 8 } & Absoluta & $\%$ & Absoluta & $\%$ & Absoluta & $\%$ \\
\hline Pouco & 5 & 21,7 & 13 & 37,1 & 1 & 12,5 \\
\hline Sim & 17 & 73,9 & 19 & 54,3 & 7 & 87,5 \\
\hline Não & 1 & 4,3 & 3 & 8,6 & - & - \\
\hline Total & 23 & 100,0 & 35 & 100,0 & 8 & 100,0 \\
\hline
\end{tabular}

Tabela 3 - Cultivo de produtos agrícolas em áreas de encostas.

\begin{tabular}{l|c|c|c|c|c|c}
\multirow{3}{*}{ Alternativas } & \multicolumn{6}{|c}{ Frequências } \\
\cline { 2 - 8 } & Silveira Martins & \multicolumn{2}{|c|}{ Ivorá } & \multicolumn{2}{c}{ Nova Palma } \\
\cline { 2 - 8 } & Absoluta & $\%$ & Absoluta & $\%$ & Absoluta & $\%$ \\
\hline Pouco & 4 & 17,4 & 6 & 17,1 & - & - \\
\hline Sim & 10 & 43,5 & 26 & 74,3 & 7 & 87,5 \\
\hline Não & 9 & 39,1 & 3 & 8,6 & 1 & 12,5 \\
\hline Total & 23 & 100,0 & 35 & 100,0 & 8 & 100,0 \\
\hline
\end{tabular}


índice de produtores nessa situação, com 91,4\%, devendo-se, talvez, à maior quantidade de lavouras de fumo do município, que tradicionalmente são cultivadas em áreas declivosas.

\section{Da prática de fertilização dos cultivos agrícolas pelos produtores regionais}

Esse tipo de prática é extremamente nociva ao ambiente quando não é bem executada e realizada fora das técnicas e recomendações, principalmente aos corpos d’água e lençol freático. Quando aplicados em grandes quantidades, podem vir a contaminar os corpos hídricos através da lixiviação e escoamento superficial das áreas agrícolas a montante.

A Tabela 4 mostra as frequências e porcentagens relativas à utilização de fertilizantes no cultivo agrícola nas unidades de produção, sendo ele de origem química ou orgânica.

Observa-se que a grande maioria dos produtores utiliza fertilizantes em seus cultivos, tanto na forma química quanto na forma orgânica, sendo aplicada, muitas vezes, em altas doses e podendo ser uma fonte de contaminação dos cursos d'água a jusante. Portanto, a utilização de fertilizantes sem critérios técnicos definidos pode se tornar um fator de degradação ambiental, pois os resíduos aplicados diretamente no solo, no caso de uma enxurrada acarreta um escoamento superficial, serão carreados para cotas mais baixas. As culturas anuais, como soja, milho e fumo nestas áreas, necessitam de um aporte nutricional via fertilização para que se alcancem altas produtividades.

Segundo Fernandez e Garcia (2001), a percepção dos agricultores, os recursos locais, a disponibilidade de recursos financeiros e os objetivos estabelecidos são os condicionantes que determinarão o padrão tecnológico adequado, visto que a depleção dos agroecossistemas pode advir da utilização de técnicas impróprias para as áreas.

Tais culturas, com exceção do fumo, não remuneram adequadamente os produtores por se tratar de commodities que têm sua cotação atrelada ao câmbio, onde ocorrem constantes flutuações e variações nos preços de mercado. Isso leva o produtor a não receber uma remuneração digna sobre o seu produto, pois não produz em grande escala que possibilite a ele uma capacidade maior de investimento e de suprir suas necessidades básicas.

Uma alternativa para essas áreas seria a utilização de culturas perenes com maior valor comercial onde não haveria o revolvimento do solo. Nessa opção será relevante, uma cultura na qual fosse possível

Tabela 4 - Frequência de utilização de fertilizantes na produção agrícola.

\begin{tabular}{l|c|c|c|c|c|c}
\multirow{3}{*}{ Alternativas } & \multicolumn{7}{|c|}{ Frequências } \\
\cline { 2 - 8 } & Silveira Martins & \multicolumn{2}{|c|}{ Ivorá } & \multicolumn{2}{c}{ Nova Palma } \\
\cline { 2 - 8 } & Absoluta & $\%$ & Absoluta & $\%$ & Absoluta & $\%$ \\
\hline Pouco & 1 & 4,3 & 2 & 5,7 & - & - \\
\hline Sim & 21 & 91,3 & 31 & 88,6 & 8 & 100,0 \\
\hline Não & 1 & 4,3 & 2 & 5,7 & - & - \\
\hline Total & 23 & 100,0 & 35 & 100,0 & 13 & 100,0 \\
\hline
\end{tabular}

agregar valor no produto final com sua elaboração, ou seja, um produto in natura que passe por um processo de industrialização e nele se agregue valor, desenvolvendo a economia regional em diferentes níveis.

\section{Destino das embalagens de agrotóxicos e defensivos agrícolas}

A Tabela 5 mostra os destinos dados às embalagens dos insumos e agrotóxicos utilizados na produção agrícola regional.

Constatou-se que, por força da legislação e da logística desenvolvida para o destino das embalagens de agrotóxicos utilizados nas produções agrícolas regionais, a maioria é devolvida à empresa que os comercializou em todos os municípios pesquisados. Em Silveira Martins, 22,2\% dos produtores utilizam técnicas como a incineração e o enterro de embalagens como prática usual de descarte. Entretanto, tal ação pode contaminar o solo, a água e mesmo a atmosfera, através da emissão de poluentes oriundos da incineração de embalagens dos agrotóxicos. Segundo Fernandez Neto e Sarcinelli (2009), as principais fontes de contaminação química dos recursos naturais são provenientes das atividades industriais e agrícolas.

O fato de existir uma legislação que controla essa prática serve para incentivar e de certa forma responsabilizar quem produz e revende esses produtos, bem como contribuir para conscientização ambiental dos produtores.

\section{Existência de proteção dos corpos hídricos nas unidades de produção agrícola}

Outra questão ambiental abordada no questionário foi a questão hídrica, pois todas as propriedades utilizam esse recurso para o abastecimento de suas casas, nas agroindústrias e alguns em sua produção agrícola através da técnica da irrigação.

Uma das questões levantadas foi a da proteção dos cursos d'água existentes na propriedade e se era prática usual utilizar proteções de nascentes, riachos, córregos e rios. A região é rica em nascentes, e é ponto de recarga de aquíferos e rios, tendo uma importância ambiental muito grande. A preservação de suas características qualitativas sejam elas químicas, físicas ou biológicas passa impreterivelmente pela proteção das fontes desse recurso, procurando manter seus atributos qualitativos inalterados. Todo e qualquer manejo dado à bacia de entorno terá

Tabela 5 - Destinos dados às embalagens de agrotóxicos nas unidades de produção.

\begin{tabular}{l|c|c|c|c|c|c|c}
\multirow{2}{*}{ Alternativas } & \multicolumn{6}{|c}{ Frequências } \\
\cline { 2 - 8 } & \multicolumn{2}{|c|}{ Silveira Martins } & \multicolumn{2}{|c}{ Ivorá } & \multicolumn{2}{c}{ Nova Palma } \\
\cline { 2 - 8 } & Absoluta & $\%$ & Absoluta & $\%$ & Absoluta & $\%$ \\
\hline Incinerado & 2 & 11,1 & 1 & 2,9 & - & - \\
\hline Galpão & 2 & 11,1 & 2 & 5,9 & - & - \\
\hline Céu aberto & - & - & 0 & 0 & - & - \\
\hline Enterrado & 1 & 5,6 & 0 & 0 & - & - \\
\hline Devolvido à empresa & 13 & 72,2 & 31 & 81,0 & 8 & 100,0 \\
\hline Total & 18 & 100,0 & 34 & 100,0 & 13 & 100,0 \\
\hline
\end{tabular}


reflexos nos cursos de água principalmente em seus aspectos qualitativos (ZAMBERLAN, 2007). Como indicadores da fragilidade natural da região, podem-se destacar suas características de relevo acidentado com altos níveis de declividade e solos pouco intemperizados, a exemplo do estudo de vulnerabilidade realizado por Santos e Pereira (2011), na região de Campos dos Goytacazes, onde a suscetibilidade ambiental quanto às águas subterrâneas e superficiais aumenta quando os solos são formados por sedimentos inconsolidados e com maior permeabilidade. A Tabela 6 mostra as porcentagens dos produtores regionais que utilizam e protegem os recursos hídricos.

Constatou-se que a maioria dos produtores mantêm protegidas as fontes de água existentes na propriedade, mantendo a vegetação ciliar de entorno, os locais isolados dos animais, evitando que se degrade e haja contaminação da água, que inclusive, muitas vezes é utilizada para o abastecimento das residências e outros múltiplos usos. Zamberlan (2007), estudando a qualidade das águas de reservatórios superficiais, constatou que os piores níveis, no que diz respeito aos parâmetros químicos e físicos da água, encontravam-se nos reservatórios onde a produção agrícola e pecuária era mais intensiva e onde a cobertura vegetal de entorno era insuficiente. Isso vem a corroborar com a tese de que as áreas de entorno dos mananciais têm de ter sua vegetação preservada ou possuir um manejo racional e alicerçado em técnica que minimize os impactos ambientais.

\section{Grau de interesse em participar de projetos ou programas de desenvolvimento socioeconômico regional sustentável}

A Tabela 7 demonstra o interesse do produtor em participar de programas de desenvolvimento econômico regional baseado nos princípios de sustentabilidade. Observou-se que, no município de Silveira Martins, 69,6\%

Tabela 6 - Frequência da utilização de proteções dos corpos hídricos nas unidades de produção da Quarta Colônia.

\begin{tabular}{l|c|c|c|c|c|c}
\multirow{2}{*}{ Alternativas } & \multicolumn{7}{c}{ Frequências } \\
\cline { 2 - 7 } & \multicolumn{2}{|c|}{ Silveira Martins } & \multicolumn{2}{|c|}{ Ivorá } & \multicolumn{2}{c}{ Nova Palma } \\
\cline { 2 - 7 } & Absoluta & $\%$ & Absoluta & $\%$ & Absoluta & $\%$ \\
\hline Pouco & 1 & 4,3 & 3 & 9,1 & 1 & 12,5 \\
\hline Sim & 15 & 65,2 & 24 & 72,7 & 6 & 75,0 \\
\hline Não & 7 & 30,4 & 6 & 18,2 & 1 & 12,5 \\
\hline Total & 23 & 100,0 & 33 & 100,0 & 8 & 100,0 \\
\hline
\end{tabular}

Tabela 7 - Proporção de produtores em relação ao interesse em participar de projetos de desenvolvimento regionais sustentáveis.

\begin{tabular}{l|c|c|c|c|c|c}
\multirow{3}{*}{ Alternativas } & \multicolumn{7}{|c}{ Frequências } \\
\cline { 2 - 8 } & \multicolumn{2}{|c|}{ Silveira Martins } & \multicolumn{2}{|c|}{ Ivorá } & \multicolumn{2}{c}{ Nova Palma } \\
\cline { 2 - 7 } & Absoluta & $\%$ & Absoluta & $\%$ & Absoluta & $\%$ \\
\hline Pouco & 4 & 17,4 & 5 & 14,3 & 1 & 12,5 \\
\hline Sim & 16 & 69,6 & 28 & 80,0 & 5 & 62,5 \\
\hline Não & 3 & 13,0 & 2 & 5,7 & 2 & 25,0 \\
\hline Total & 23 & 100,0 & 35 & 100,0 & 8 & 100,0 \\
\hline
\end{tabular}

estariam dispostos a se engajar em um programa dessa natureza se porventura fosse implementado, 17,4\% talvez se interessassem e 13\% não participariam. Em Ivorá, 80\% estariam dispostos, 5,7\% não se interessariam e 14,3\% estariam pouco interessados. Na região de Nova Palma, 62,5\% demonstraram interesse, $25 \%$ não e $12,5 \%$ mostraram-se pouco interessados.

Há, por parte dos produtores da quarta colônia de imigração italiana, um evidente interesse em participar de projetos cujo objetivo seja criar desenvolvimento em sua forma mais plena para a região. Visto que, atualmente, por falta de oportunidades, a alternativa dos mais jovens é deixar as propriedades rurais e migrar para as cidades em busca de estudo e principalmente de oportunidades de trabalho, não mais retornando.

\section{CONSIDERAÇÕES FINAIS}

Segundo Rucheinsky (2004), atualmente existe um impasse, pois, é preciso gerar emprego e renda e, para isso, necessita-se de mais consumo, que gera mais produção, que gera uma utilização maior dos recursos naturais, que gera mais renda do trabalho e novamente se amplia o consumo. A introdução da gestão ambiental nessas áreas é imperativa para a manutenção do meio ambiente aliada a técnicas modernas de produção que sejam adaptadas ao tipo de solo, topografia e que procure respeitar e otimizar a cultura da sociedade regional.

A agricultura é a mola mestra propulsora do crescimento econômico, desde que se tenham níveis elevados na alocação de recursos (MOURA et al., 1999). A sustentabilidade ambiental local exige que se conheçam as diversas unidades naturais a serem manejadas e se adapte a produção às leis ecológicas que mantém as capacidades dos ecossistemas (FERNANDEZ \& GARCIA, 2001).

Outro problema reside em áreas de encostas com declives muito acentuados, de acordo ao código florestal, que são ambientes de preservação e, no caso, a expansão da agricultura estaria inviabilizada legalmente, restando ao produtor manter a área atual e trabalhar com foco na verticalização produtiva das culturas.

O grande desafio, segundo Rodrigues et al. (2006), está no acesso à tecnologia de produção e de agregação de valor aos produtos agrícolas. Segundo (FERNANDEZ \& GARCIA, 2001), a estabilidade dos agroecossistemas pode ser obtida quando se faz opção por tecnologias que melhor se adaptam às necessidades e recursos dos agricultores.

O gerenciamento ambiental apresenta-se como um negócio vantajoso e um instrumento de competitividade (VERDOLIN \& ALVES, 2005). Se adotados cuidados ambientais na produção, esse pode ser um diferencial importante na comercialização dos produtos da região e a garantia de sustentabilidade.

Portanto, é importante buscar alternativas para a viabilização da produção agrícola dessas áreas, com base em pesquisa e utilização de tecnologias próprias para a região, que visem à verticalização da produtividade e cultivo de espécies de maior valor agregado ou que explorem o potencial cultural 
da região da Quarta Colônia de Imigração Italiana, relacionando-se com outros setores da economia, como a indústria e o comércio.

\section{CONCLUSÕES}

As principais atividades exercidas pelos produtores da região da Quarta Colônia de Imigração Italiana, no Rio Grande do Sul, são produção e comércio.

Os produtores da região estão bem informados com relação a novas técnicas de cultivo e de conservação do meio ambiente.

Devido à própria topografia regional, a maior parte dos cultivos está localizada em áreas de encosta, aumentando o potencial de risco de depleção dos recursos naturais. Nos municípios pesquisados, a conscientização por parte dos produtores se fez presente em mais de $50 \%$ do total pesquisado, onde foi constatado que a maioria deles utiliza alguma prática conservacionista apesar de serem cultivadas intensivamente as encostas, principalmente pela cultura do fumo. A proteção dos recursos hídricos, como mata ciliar e até mesmo proteções artificiais, é adotada por grande parte dos produtores. A maioria utiliza fertilização seja química ou orgânica em seus cultivos.

As embalagens de agrotóxicos utilizadas nas unidades de produção agrícola nos municípios da Quarta Colônia são, em sua maior parte, devolvidas nas empresas que os comercializaram. O armazenamento em galpões aparece como o segundo destino mais usado, seguido da prática da incineração, e uma pequena porcentagem ainda enterra as embalagens vazias.

Foi constatado, também, que os produtores regionais possuem interesse em participar de programas que visem ao desenvolvimento agrícola sustentável da Quarta Colônia. Para tanto, faz-se necessário desenvolver técnicas e equipamentos voltados à produção nessas áreas, fomentando, por exemplo, o plantio de culturas perenes de alto valor agregado, aproveitando a cultura e as potencialidades locais.

\section{REFERÊNCIAS}

BRASIL. (1973) Ministério da Agricultura. Departamento Nacional de Pesquisa Agropecuária. Levantamento de reconhecimento de solos do Estado do Rio Grande do Sul. Recife. (Boletim técnico, n. 30).

CARVALHO, I.C.M. (2001) Qual educação ambiental? Elementos para um debate sobre educação ambiental e extensão rural. Revista Agroecologia e Desenvo/vimento Rural Sustentável, v. 2, n. 2, p. 43-51.

FERNANDEZ NETO, M.L. \& SARCINELLI, P.N. (2009) Agrotóxicos em água para consumo humano: uma abordagem para avaliação de risco e contribuição ao processo de atualização da legislação brasileira. Revista Engenharia Sanitária e Ambiental, v. 14, n. 1, p. 69-78.

FERNANDEZ, X.S. \& GARCIA, D.D. (2001) Desenvolvimento rural sustentável: uma perspectiva agroecológica. Revista Agroecologia e Desenvolvimento Rural Sustentável, v. 2, n. 2, p. 17-26.

GONÇALVES, C.S.; RHEINHEIMER, D.S.; PELLEGRINI, J.B.R.; KIST, S.L. (2005) Qualidade da água numa microbacia hidrográfica de cabeceira situada em região produtora de fumo. Revista Brasileira de Engenharia Agrícola e Ambiental, v. 9, n. 3, p. 391-399.

ITAQUI, J. (2002) Quarta Colônia: inventários técnicos. Condesus Quarta Colônia. Santa Maria.

LAGO, A. \& PÁDUA, J.A. (1984) O que é ecologia. São Paulo: Editora Brasiliense.

LEFF, E. (2002) Agroecologia e saber ambiental. Revista Agroecologia e Desenvolvimento Rural Sustentável, v. 3, n. 1, p. 36-51.

MARCUZZO, S.; PAGEL, S.M.; CHIAPPETTI, M.IS. (1998) A reserva de biosfera da Mata Atlântica do Rio Grande do Sul. Caderno n. 11. CETESB. São Paulo.

MERTEN, G.H. \& MINELLA, J.P. (2004) Qualidade da água em bacias hidrográficas rurais: um desafio atual para a sobrevivência futura.
Revista Agroecologia e Desenvolvimento Rural Sustentável, v. 3, n. 4 p. 33-38.

MORENO, J.A. (1961) Clima do Rio Grande do Sul. Porto Alegre: Secretaria da Agricultura e Abastecimento, Diretoria de Terras e Colonização, Secção de Geografia.

MOURA, J.G.; CÂMARA, S.F.; LIMA, R.C. (1999) Expansão agrícola e crescimento econômico: uma avaliação com dados transversais. Revista Organizações Rurais e Agroindustriais. UFLA, v. 1, n. 2, p. 31-42.

NEUMANN, P.S. \& LOCH, C. (2002) Legislação ambiental, desenvolvimento rural e práticas agrícolas. Revista Ciência Rural. UFSM, v. 32. n. 2, p. 243-249.

RODRIGUES, G.S.; CAMPANHOLA, C.; RODRIGUES, I.; FRIGHETTO, R.T.S.; VALARINI, P.; RAMOS FILHO, L.O. (2006) Gestão ambiental de atividades rurais: estudo de caso em agroturismo e agricultura orgânica. Revista agricultura São Paulo, v. 53, n. 1, p. 17-31.

RUCHEINSKY, A. Sustentabilidade: uma paixão em movimento. Porto Alegre: Editora Sulina.

SANTOS, M.G. \& PEREIRA, S.Y. (2O11) Método AVI (Aquifer Vulnerability Index) para a classificação da vulnerabilidade das águas subterrâneas na região de Campos dos Goytacazes, Rio de Janeiro. Revista Engenharia Sanitária e Ambiental, v. 16, n. 3, p. 281-290.

VERDOLIN, D.R. \& ALVES, A.F. (2005) Responsabilidade social: perspectivas para o agronegócio. Revista Organizações Rurais Agroindustriais, v. 7, n. 1, p. 103-113.

ZAMBERLAN, J.F. (2007) Caracterização de águas de reservatórios superficiais para uso em microirrigação. Dissertação (Pós-graduação em engenharia agrícola - Universidade Federal de Santa Maria). Santa Maria. 